\title{
Mitochondrial mass governs the extent of $T$ cell senescence
}

\section{Lauren A. Callender ${ }^{1,3}$, Elizabeth C. Carroll ${ }^{1,3}$, Emilia A Bober $^{1}$, Arne N. Akbar ${ }^{2}$, Egle Solito',} Sian M. Henson ${ }^{1^{*}}$.

${ }^{1}$ Translational Medicine and Therapeutics, William Harvey Research Institute, Barts and The London School of Medicine and Dentistry, Queen Mary University of London, Charterhouse Square, London EC1M 6BQ, UK

${ }^{2}$ Division of Infection and Immunity, Department of Immunology, University College London, London W1T 4JF, UK

${ }^{3}$ Both authors contributed equally

${ }^{*}$ Correspondence:

Dr. Sian M. Henson.

s.henson@qmul.ac.uk

\section{Keywords}

Ageing, mitochondria, metabolism, T cell, senescence 


\section{Abstract}

The susceptibility of human $\mathrm{CD} 4^{+}$and $\mathrm{CD} 8^{+} \mathrm{T}$ cells to senesce differs, with $\mathrm{CD} 8^{+} \mathrm{T}$ cells acquiring an immunosenescent phenotype faster than their $\mathrm{CD}^{+} \mathrm{T}$ cell compartment. We show here that it is the inherent difference in mitochondrial content that drives this phenotype, with senescent human $\mathrm{CD}^{+} \mathrm{T}$ cells displaying a higher mitochondrial mass. The loss of mitochondria in the senescent human $\mathrm{CD}^{+} \mathrm{T}$ cells has knock-on consequences for nutrient usage, metabolism and function. Mitochondrial dysfunction has been linked to both cellular senescence and ageing, however it is still unclear whether mitochondria play a causal role in senescence. Our data shows that reducing mitochondrial function in human $\mathrm{CD}^{+} \mathrm{T}$ cells, through the addition of low dose rotenone, causes the generation of a $\mathrm{CD} 4^{+} \mathrm{T}$ cell with a $\mathrm{CD} 8^{+}$- like phenotype. Therefore we wish to propose that it is the inherent metabolic stability that governs the susceptibility to an immunosenescent phenotype. 


\section{Introduction}

The human immune system functionality declines with age in a process referred to as immunosenescence. The functional outcomes of this process include the compromised ability of older individuals to mount protective immune responses against both previously encountered and new pathogens ${ }^{1}$. Additionally, there is a marked decrease in vaccine efficacy in these populations ${ }^{1}$. While these age-associated alterations arise from defects in different leukocyte populations, the dysfunction is most profound in T cell subsets ${ }^{2}$. Furthermore, ageing is associated with a chronic low grade inflammatory state, termed inflammaging ${ }^{3}$ and mediates an important role in a range of age-related degenerative pathologies ${ }^{4}$. The source of this inflammation has yet to be defined. Senescent $\mathrm{T}$ cells are found to accumulate with age and represent a likely contributor to this inflammatory state that is observed during ageing ${ }^{1}$.

Primary human senescent T cells are a highly differentiated subset of cells found within the CD27 CD28- population $^{5,6}$. This subset can be further characterised on the basis of CD45RA expression, with highly differentiated $T$ cells that re-express CD45RA identified as the senescent $T$ cell population (EMRA; effector memory CD45RA re-expressing $\mathrm{T}$ cells). They display multiple characteristics of senescence including a low proliferative activity, high levels of DNA damage and loss of telomerase activity ${ }^{7,8}$. However the response patterns of $\mathrm{CD}^{+}$and $\mathrm{CD} 8^{+} \mathrm{T}$ cells to ageing differs, with $\mathrm{CD}^{+} \mathrm{T}$ cells being more susceptible to both phenotypic and functional changes during ageing $^{9,10}$. The CD8 ${ }^{+}$EMRA T cell subset accumulate in higher proportions with age and are more prevalent following in vitro culture than the $C D 4^{+} \mathrm{EMRAs}^{9}$. The cause of this difference has been suggested to be due to the differing homeostatic mechanisms and an increased gene expression instability of regulatory cell surface molecules in the $\mathrm{CD}^{+}$EMRA subset ${ }^{9}$. We would like to postulate an alternate view, that CD4 ${ }^{+}$EMRA T cells are more metabolically robust and therefore better able to withstand the intrinsic or extrinsic effects governing differentiation.

Metabolic examination of $\mathrm{CD} 4^{+}$and $\mathrm{CD} 8^{+} \mathrm{T}$ cells suggest that their metabolic programming allows differential immunological functions to be performed. We demonstrate here that $\mathrm{CD} 4^{+} \mathrm{T}$ cells have a greater mitochondrial mass and are consistently more oxidative than CD8 ${ }^{+} \mathrm{T}$ cells, allowing them 
to sustain effector function. Whereas the metabolic programs that prioritise rapid biosynthesis such as glycolysis are favoured by $\mathrm{CD} 8^{+} \mathrm{T}$ cells, allowing for faster growth and proliferative rates ${ }^{11,12}$. We have previously shown that $\mathrm{CD}^{+}$EMRA T cells display impaired mitochondrial function ${ }^{8}$ but are still unclear as to whether $\mathrm{CD}^{+}$EMRA $\mathrm{T}$ cells also exhibit mitochondrial dysfunction. We provide evidence that this is not the case, CD4 $4^{+}$EMRA T cells have fitter, healthier mitochondria that are better able to meet the energy requirements of the CD4 ${ }^{+}$EMRA subset. Therefore we propose that it is the inherent metabolic stability that governs the susceptibility to an immunosenescent phenotype. 


\section{Results}

\section{Human CD4 ${ }^{+}$EMRA T cells development at a slower rate due to their higher mitochondrial content}

Human $T$ cells can be subdivided into four populations on the basis of their relative surface expression of CD45RA and CD27 molecules (Supplementary Figure 1A). The four subsets are defined as, naïve $\left(\mathrm{N}\right.$; $\left.\mathrm{CD}_{4} \mathrm{RA}^{+} \mathrm{CD} 27^{+}\right)$, central memory $\left(\mathrm{CM}\right.$; $\left.\mathrm{CD}_{4} \mathrm{RA}^{-} \mathrm{CD} 27^{+}\right)$, effector memory (EM; CD45RA ${ }^{-} C D 27^{-}$), and effector memory $T$ cells that re-express CD45RA (EMRA;

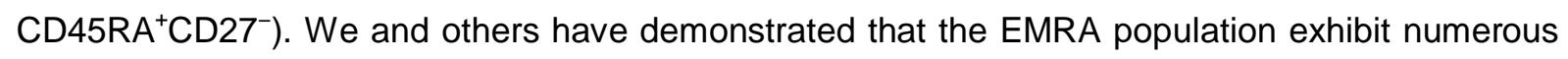
characteristics of senescence $8,13,14$, indeed it has also been known for some time that CD4 ${ }^{+}$EMRA $\mathrm{T}$ cells senesce at a slow rate than their $\mathrm{CD}^{+}$counterparts (Figure $1 \mathrm{~A}$ ). It was thought that the difference in EMRA accumulation was due to their differing cytokine stabilities ${ }^{9}$, however we now demonstrate that it is a difference in mitochondrial mass between $C D 4^{+}$and $C D 8^{+}$EMRAs that governs the rate at which they develop.

Using MitoTracker Green, a mitochondrial-specific dye that binds the mitochondrial membranes independently of mitochondrial membrane potential (MMP), we found the CD4+ EMRA subset to have a significantly higher mitochondrial mass than $C D 8^{+}$EMRAs, nearly double the amount of mitochondrial content (Figure 1B). The $\mathrm{CD}^{+}$EMRA subset retain their mitochondrial content copared to earlier less differentiated subsets (Supplementary Figure $2 \mathrm{~A}$ ) where as the CD8 ${ }^{+}$ EMRAs do not ${ }^{8}$. This was also borne out when the EMRA subsets were examined ex-vivo by electron microscopy. We observed significantly fewer mitochondrial in the $\mathrm{CD}^{+}$EMRA compartment when compared to the $\mathrm{CD} 4^{+}$EMRA fraction using a point counting method (Figure 1C). Furthermore when we investigated the expression of PGC1a (peroxisome proliferatoractivated receptor gamma coactivator 1-alpha), the key regulator of mitochondrial biogenesis, the CD4 ${ }^{+}$EMRA subset showed significantly higher ex-vivo levels of this marker than the CD8 ${ }^{+}$EMRAs (Figure 1D). Collectively our results demonstrate that senescent $\mathrm{CD}^{+} \mathrm{T}$ cells have increased mitochondrial mass in comparison to their $\mathrm{CD} 8^{+}$counterparts.

\section{Distinct mitochondrial functions in $\mathrm{CD}^{+}$and CD8 ${ }^{+}$EMRA subsets}


The increased mitochondrial mass seen in the CD4 ${ }^{+}$EMRA subsets suggest they may exhibit distinct mitochondrial functions compared to the $\mathrm{CD}^{+}$EMRAs. Indeed using TMRE, which measures mitochondrial transmembrane potential, we found the CD4 ${ }^{+}$EMRAs had a higher proportion of hyperpolarised mitochondria than the $C D 8^{+}$EMRA subset, which displayed a hypopolarised phenotype (Figure 2A). Hyperpolarised mitochondria can be a source of reactive oxygen species (ROS), which has the potential to drive senescence ${ }^{15}$. Mitochondrial ROS, measured using MitoSox, was found to be significantly higher in CD4+ EMRAs (Figure 2B), however this increase was neutralised owing to the higher mitochondrial mass, meaning that CD8 ${ }^{+}$ EMRA T cells produced more ROS per mitochondria that can potentially enhance their senescent phenotype (Figure 2C). Furthermore increased ROS can also cause DNA damage and the activation of the DNA damage response, elevated during senescence. The examination of phosphorylated $\mathrm{H} 2 \mathrm{AX}(\mathrm{YH} 2 \mathrm{AX})$, a member of the histone $\mathrm{H} 2 \mathrm{~A}$ family that is part of the DNA damage response, in EMRAs revealed that the $C D 8^{+}$EMRA subset displayed a higher level of this marker compared to CD4 ${ }^{+}$EMRAs (Figure 2D). However both EMRA subsets express the highest amount of DNA damge compared to their less differentiaited subsets (data not shown). We suggest that a loss of mitochondrial mass in the $C D 8^{+}$EMRA subsets is a key mediator in generating an enhanced senescent state.

We then examined differences in mitochondrial respiration between the CD4 ${ }^{+}$and $C D 8^{+}$EMRA subsets. Differences were found in both the baseline respiration and respiration following injection of oligomycin, FCCP and rotenone and antimycin A (Figure 2E). The CD4+ EMRA population retain their ability to respond to challenge akin to the other $\mathrm{CD} 4^{+}$memory subsets (Supplementary Fig.2B), while we have shown this not to be the case for the $C D 8^{+}$EMRA compartment ${ }^{7}$. The oxygen consumption rate $(\mathrm{OCR})$, together with the spare respiratory capacity, the potential amount of stored energy a cell has to respond to challenge, were both upregulated in CD4 $4^{+}$EMRAs. Further implying a difference in mitochondrial content. While the extracellular acidification rate (ECAR), a marker of lactic acid production and glycolysis was only marginally increased compared to the $\mathrm{CD}^{+}$EMRA subset (Figure 2F). Furthermore the amount of ATP made by CD4 ${ }^{+}$EMRAs was also greater than that of the $\mathrm{CD}^{+} \mathrm{s}$ (Figure $2 \mathrm{G}$ ). These results suggest that the $\mathrm{CD} 4^{+} \mathrm{EMRA}$ 
subset have enhanced mitochondrial fitness that allows for a greater flexibility in the type of metabolism they can engage.

\section{CD8+ EMRA T cells display impaired nutrient uptake}

T cells utilise a variety of energy sources including glucose and lipids, however their metabolic preferences are governed not only by their differentiation status but also by mitochondria fitness ${ }^{16}$. Indeed a lack of regulatory control over nutrient usage is a recurrent theme accompanying senescence and ageing ${ }^{17}$. We therefore sort to determine whether there were differences in glucose and fatty acid uptake in $\mathrm{CD} 4^{+}$and $\mathrm{CD} 8^{+}$EMRA T cell subsets. CD4 ${ }^{+}$EMRAs were found to take up more of the fluorescent glucose analogue 2-NBDG from their extracellular environment than their $\mathrm{CD}^{+}$EMRA counterparts (Figure 3A). Indeed $C D 4^{+}$EMRAs showed higher expression of Glut-1, the major glucose transporter in T cells using an RNA-labelled probe (Figure 3B). Analysis of microarray data revealed high expression of alternate glut family members ${ }^{18}$. Interestingly CD8 ${ }^{+}$EMRAs displayed a higher expression of the class III glucose transporters Glut8 and -10 (Figure 3B). Both these transporters are found intracellularly and are thought to transport glucose or galactose across intracellular organelle membranes ${ }^{19}$. The uptake of fluorescently labelled palmitate, BODIPY C16, a long chain fatty acid was also quantified. Similar to our observations for glucose uptake, CD4 ${ }^{+}$EMRA T cells also utilise significantly more palmitate than their $\mathrm{CD}^{+}$counterparts (Figure $3 C$ ). Furthermore $C D 4^{+}$EMRA T cells express higher levels of both the fatty acid translocase CD36 and the fatty acid transporters FATP-2 and -3 (Figure 3D). Taken together these results suggest that the increased mitochondrial fitness of CD4 ${ }^{+}$EMRA T cells enable these cells to better utilise glucose and lipids, which may limit the impact of senescence.

\section{Impaired proliferation and migration of CD8 ${ }^{+}$EMRA T cells}


The end result of the DNA damage response is the activation of p53. p53 regulates cell cycle arrest limiting cell growth and proliferation, as well as playing a crucial role in limiting cell motility, a critical process for optimal T cell function ${ }^{20}$. In line with the theory that the acquisition of the CD4 ${ }^{+}$ EMRA $T$ cell subset occurs at a slower rate than their $C D 8^{+}$counterpart, we find that the expression of $p-p 53$ is higher in the $C D 8^{+}$EMRAs compared to the CD4 ${ }^{+}$(Figure 4A). Although the expression of p-p53 in the CD4 ${ }^{+}$EMRAs is the highest of all the CD4 $4^{+}$memory subsets (data not shown). Furthermore the proliferative defect is more pronounced CD8 ${ }^{+}$EMRA subset, measured using ki67 (Figure 4B) and migration impaired (Figure 4C). Transwell chemotactic assays were used to assess migration, HUVECs were activated using $20 \%$ autologous donor sera, in order to create a more appropriate ex vivo environment and was found to be no different to activation with IFNY (Supplementary Figure 3). Migration was assessed in response to CXCL10 and CXCL12, chemokines promoting the migration of memory T cells or $20 \%$ autologous serum. $\mathrm{CD}^{+}$EMRA T cells were less able to respond to CXCL10 and -12 than autologous serum, presumably due to the loss of CXCR3 and -4 from the CD4 $4^{+}$EMRA T cells ${ }^{21,22,23}$. CD8 ${ }^{+}$EMRAs on the other hand retain expression of CXCR3 and -4 and migrate in response to both chemokines and autologous serum, all be it to a lesser extent than their CD4 ${ }^{+}$counterparts (Figure $4 C$ ).

The enhanced migratory capacity of the CD4 ${ }^{+}$EMRA subset was also evident in their enhanced cortactin expression (Figure 4D). Cortactin is known to mediate complex roles in cell migration and invasion $^{24}$; where it is involved in the formation of lamellipodia and invadiopodia ${ }^{25,26}$. Furthermore the loss of p53 has been shown to promote invasion ${ }^{27}$. Taken together with the findings that p53 inhibits mitochondrial biogenesis, $C D 4^{+}$EMRAs potentially retain more functionality than their $\mathrm{CD} 8^{+}$ counterpart, as they are better able to undergo the necessary metabolic reprogramming needed to generate effector functions owing to their higher mitochondrial mass.

\section{Impairing mitochondrial function in $\mathrm{CD4}^{+} \mathrm{T}$ cells accelerates senescence}

We then wanted to investigate whether impairing mitochondrial function in $\mathrm{CD}^{+} \mathrm{T}$ cells could induce a similar phenotype observed in the $\mathrm{CD}^{+}$compartment. We used rotenone, a complex I inhibitor, to damage mitochondria. After a 5 day treatment with a low dose $(10 \mathrm{nM})$ rotenone we 
observed an increased amount of low mass mitochondria at the expense of the higher more functional fused mitochondria in $\mathrm{CD}^{+} \mathrm{T}$ cells (Figure $5 \mathrm{~A}$ ). The change in mitochondrial state lead to a switch in metabolism, with the rotenone treated $\mathrm{CD} 4^{+} \mathrm{T}$ cells showing a strong response to the addition of glucose akin to the $\mathrm{CD}^{+} \mathrm{T}$ cells (Figure 5B). The rotenone treatment increased the basal glycolysis levels as well as increasing the glycolytic capacity of CD4+ $\mathrm{T}$ cells (Figure $5 \mathrm{C}$ ). There is growing evidence that p53 can also regulate mitochondrial function, maintaining mitochondrial respiration through the transactivation of SCO2 (synthesis of cytochrome c oxidase $2)^{28}$. However stress conditions led to the translocation of p53 from the nucleus to the mitochondria leading to mitochondria mediated apoptosis ${ }^{29}$. We observe here that treatment of CD4 ${ }^{+} \mathrm{T}$ cells with rotenone leads to high levels of phospho-p53 (Figure 5D) and a slowing in cell growth that eventually lead to a loss of $C D 4^{+} \mathrm{T}$ cells (Figure $5 \mathrm{E}$ ). Therefore leading us to conclude that the higher mitochondrial mass observed in $\mathrm{CD}^{+} \mathrm{T}$ cells is protective against senescence by maintaining an oxidative state. 


\section{Discussion}

Immunosenescence is a hallmark feature of ageing and is accompanied by a chronic low grade inflammatory state. Together these features are important drivers in numerous age-related pathologies $^{30}$. Senescent or EMRA T cells are a highly dynamic and heterogeneous subset of cells that accumulate with age ${ }^{18}$ and are found in both the $\mathrm{CD} 4^{+}$and $\mathrm{CD} 8^{+} \mathrm{T}$ cell compartments. We and others have shown the $\mathrm{CD}^{+}$EMRA subset to accumulate more rapidly than their $\mathrm{CD} 4^{+}$ counterparts with age $\mathrm{e}^{9,31,32}$. Both subsets undergo the same phenotypic and functional changes, showing loss of co-stimulatory molecules and the acquisition of NK cell markers, together with a reduction in proliferative capacity and changes in cytokine production. It has been suggested that the $C D 4^{+}$EMRA subset is more resistant to the effects of age owing to better homeostatic control in this compartment compared to that of $\mathrm{CD}^{+} \mathrm{T}$ cells. However we show here that it is enhanced mitochondrial dysfunction in the CD8 ${ }^{+}$EMRA subset that alters metabolic stability that governs the susceptibility of an immunosenescent state.

Mitochondrial dysfunction is a central event in many pathologies and contributes to age-related processes. Mitochondria have been shown to participate in every aspect of aging, such as a decline in stem cell function, cellular senescence and the development of the low grade inflammatory state $^{33}$. Alterations that occur to mitochondria with age are numerous, including reductions in mitochondrial mass $^{34}$, defects in mitochondrial biogenesis ${ }^{35}$, and impaired mitochondrial function in terms of ATP production and respiratory chain capacity ${ }^{36}$. Indeed we show here that the CD8 ${ }^{+}$EMRA $T$ cell subset displayed a lower mitochondrial mass, impaired mitochondrial biogenesis, as well as having a hypopolarised mitochondrial phenotype compared to the $C D 4^{+}$EMRA subset. When taken together these data indicate that the CD8 ${ }^{+}$EMRA subsets has a greater degree of mitochondrial impairment than the $\mathrm{CD} 4^{+}$compartment. We do not wish to oversimplify the idea that the presence of highly active mitochondria increases senescence resistance, as studies have demonstrated that mild reduction of mitochondrial function can counter-intuitively increase lifespan in lower organisms ${ }^{37}$. However the overexpression of mitochondrial enzymes in yeast increases lifespan and caloric restriction ${ }^{38}$, a well-established process to increase life span, mediates its effects through improved mitochondrial activity. 
Therefore we believe that the enhanced mitochondrial function observed for the CD4 ${ }^{+}$EMRA T cell subset does confer a survival advantage at the cellular level.

Increases in ROS levels have been demonstrated to be critical for the induction and maintenance of cell senescence ${ }^{39}$. However, ROS are also secondary messengers in cellular antioxidant pathways and rather than being thought of as deleterious by products and can be beneficial through the induction of an adaptive response that counteracts the rise in oxidative stress

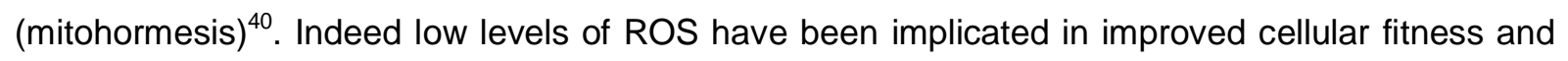
lifespan extension in various animal models ${ }^{41}$. The mitochondrial membrane potential $(\Delta \Psi \mathrm{m})$ is the central bioenergetic parameter controlling the generation of $\mathrm{ROS}^{42}$. We show here that the CD8 ${ }^{+}$ EMRA subset displayed a hypopolarised phenotype whereas the CD4 ${ }^{+}$EMRAs were in a hyperpolarised state, with both subsets showed very little protein leak. As expected from cells that display a high $\triangle \Psi \mathrm{m} \mathrm{CD} 4^{+}$EMRAs also produced more ROS than their $\mathrm{CD}^{+}$counterparts. However the higher mitochondrial content observed in CD4 $4^{+}$EMRA T cells means these cells have more buffering capacity to quench the effects of the ROS. We postulate that the CD4 ${ }^{+}$EMRAs are better at controlling the damaging effect of ROS and are therefore better able to control the rate of senescence. Similar mechanisms have been reported in hepatocytes, whereby a reduction in mitochondrial ROS production, through a decrease in proton leak and a higher $\Delta \Psi_{\mathrm{m}}$ were found to be beneficial ${ }^{43,44}$. However, it remains to be established what role uncoupling proteins (UCPs) play in mitigating ROS production by senescent $\mathrm{T}$ cells. Mouse models have shown a positive correlation between increased uncoupling and lifespan ${ }^{45}$. We can only infer a potential role for UCP1. UCP1 is activated by fatty acids and we show here that the CD4 ${ }^{+}$EMRA population take up more fatty acids and retain more fatty acid transporters than the CD8 ${ }^{+}$EMRA subset.

Mitochondria also play a key role in cellular metabolism, they house the electron transport chain and the TCA cycle, as well as playing crucial roles in the synthesis and breakdown of lipids ${ }^{46}$. Metabolic regulation plays an important role during cellular senescence, with dysregulated metabolism now identified as a feature of many different cell types including $\mathrm{T}$ cells ${ }^{47}$. There is increasing evidence that cell cultures become glycolytic as they age, depending on the senescence induction method used ${ }^{47,48}$. Indeed we have shown previously that CD8 ${ }^{+}$EMRA T 
cells as they differentiate lose their metabolic plasticity and become more glycolytic ${ }^{8}$. However, we show here that $C D 4^{+}$EMRAs retain their metabolic flexibility showing better glycolytic and oxidative capacity than their $\mathrm{CD}^{+}$counterparts. Furthermore, they also retain better glucose and lipid uptake together with increased expression of transporters. Interestingly CD8 ${ }^{+}$EMRAs displayed increased expression of the glucose transporters glut8 and -10. It is tempting to speculate in the light of a recent publication showing that glut6 functions as a glycolysis modulator in inflammatory macrophages without influencing glucose uptake ${ }^{49}$, that glut8 and -10 may act in a similar manner in senescent CD8 ${ }^{+}$T cells. Glut6, -8 and -10 are all members of the Glut III family of transporters, with glut6 and -8 being very closely located on chromosome 9 and glut10 having a very high affinity for both 2-deoxy-D-glucose and D-galactose ${ }^{50}$, both slow the rate of glycolysis. However further work needs to be carried out in order to establish whether glut8 and -10 play a negative role on glucose uptake on T cells.

The changes that occur to nutrient usage during senescence impacts T cell function, as is evident from the accelerated loss of function seen in CD8 ${ }^{+}$EMRA T cells. Senescent $C D 8^{+} \mathrm{T}$ cells showed greater impairment in proliferative capacity than their CD4+ EMRA counterparts, in part, due to their reduced ability to take up and efficiently utilise metabolites. However the phenotype seen in $\mathrm{CD}^{+}$EMRA T cells also mirrors that reported for haematopoietic cells undergoing ER stress: compromised mitochondrial function, lower ATP levels and reduced glut1 expression ${ }^{51}$. Cell metabolism also exerts a strong influence on $\mathrm{T}$ cell migration ${ }^{52}$. The improved mobilisation of energy substrates by CD4 ${ }^{+}$EMRA T cells allows them to be better equipped to deal with the high energy demands of the migration process. Interestingly the CD4 ${ }^{+}$EMRAs were unable to respond to CXCL10 and -12 , as the expression of CXCR3 and -4 have both been shown to decrease with differentiation in the $C D 4^{+}$subset but is retained by $C D 8^{+} s^{21,22,23}$. However, chemokine receptor expression in $\mathrm{CD}^{+} \mathrm{T}$ subsets does not universally decline, as the CD4 ${ }^{+}$EMRA subset show robust transmigration in response to autologous serum. The migratory advantage of CD4 ${ }^{+}$EMRA T cells may also be explained by their increased expression of cortactin, a core element of $\mathrm{T}$ cell locomotion involved in the formation of lamellipodia and invadiopodia ${ }^{25,26}$. Taken together the greater loss in proliferative and migratory capacity of senescent $\mathrm{CD}^{+} \mathrm{T}$ suggests a potential 
greater impairment to $\mathrm{CD} 8^{+}$immunity. Indeed, failure to produce an antibody response following flu vaccination has been associated with an increase in senescent $C D 8^{+} \mathrm{T}$ cells ${ }^{53}$.

We postulate here that mitochondrial density influences the extent of $\mathrm{T}$ cell senescence in a p53 dependent manner. Studies have shown that p53 can influence mitochondrial function, under steady state conditions p53 maintains mitochondrial respiration through the regulation of $\mathrm{SCO}^{28}$. $\mathrm{SCO} 2$ is critical for regulating the cytochrome c oxidase (COX) complex, the major site of oxygen utilisation. However under stress settings p53 functions to control mitochondrial quality through the overexpression of SCO2, ROS generation and the removal of mitochondria ${ }^{29}$ via mitophagy or a protease-dependent degradation of damaged proteins ${ }^{54}$. We show here that the relatively lower expression of p53 in $\mathrm{CD}^{+}$versus $\mathrm{CD}^{+}$EMRA T cells maintains an oxidative metabolism, increasing mitochondrial stress in the $\mathrm{CD} 4^{+} \mathrm{T}$ cells leads to a more $\mathrm{CD} 8^{+}$like glycolytic metabolism that is accompanied by increased apoptosis. Our work goes against findings in fibroblasts where the targeted depletion of mitochondria through the impairment of their biogenesis demonstrated that decreased numbers of mitochondria were able to prevent the senescence response ${ }^{55}$. It is possible that for T cells, therapies aimed at increasing mitochondrial mass would be beneficial in combating the detrimental effects of senescence during ageing.

Collectively our results suggest that mitochondrial mass controls the senescence phenotype in $\mathrm{T}$ cells. However the mechanism remains elusive, it is not via a DNA damage response that has been suggested by others ${ }^{55}$. Mitochondria are a central part in inducing and governing the rate of $\mathrm{T}$ cell senescence. Therefore identifying $T$ cell specific therapies aimed at increasing mitochondrial mass would be beneficial in combating the detrimental effects of senescence during ageing. 


\section{Experimental Procedures}

\section{Blood sample collection, isolation and cell culture}

Heparinised peripheral blood samples were taken from healthy volunteers, average age 41 years \pm 5. Healthy was taken as individuals who had not had an infection or immunisation within the last month, no known immunodeficiency or history of chemotherapy or radiotherapy, and were not receiving systemic steroids within the last month or any other immunosuppressive medications within the last 6 months. PBMC were isolated using Ficoll hypaque (Amersham Biosciences). All samples were obtained in accordance with the ethical committee of Royal Free and University College Medical School and the North East-York Research Ethics Committee 16/NE/0073. Human umbilical vein endothelial cells (HUVECs) were cultured according to the supplier's instructions (Promocell)

\section{Flow cytometric analysis and cell sorting}

Flow cytometric analysis was performed using the following antibodies: CD4 PECF594 (RM4-5) from BD Biosciences and CD8 PerCP (SK1), CD45RA BV605 (HI100), CD27 BV421 (O323), CD28 BV785 (CD28.2), CCR7 PECy7 (G043H7), CD36 APCCy7 (5-271) from BioLegend. FATP2 (Abcam) and FATP3 (Atlas antibodies) were measured in conjunction with goat anti-rabbit AF488 (Abcam). Cortactin expression was assessed using rabbit anti-human cortactin antibody (PA527134; Life Technologies) stained in conjugation with goat anti-rabbit Cy3 (Life Technologies). PGC1 $\alpha$ (3G6), p-p53 (16G8) both from Cell Signaling, and Ki67 (B56; BD Bioscience) were assessed by intracellular staining using solution AB (ThermoFisher) and goat anti-rabbit AF488 (Abcam). All samples were run using an LSR II (BD Biosciences) and analysed using FlowJo software (Treestar).

Magnetic beads were used to isolation of $\mathrm{CD}^{+}$and $\mathrm{CD}^{+} \mathrm{T}$ cells (Miltenyi Biotec) according to the manufacturer's instructions. The purity of T cell subsets was assessed by flow cytometry.

\section{PrimeFlow RNA assay}

PrimeFlow RNA Assay technology was used to determine SLC2A gene expression according to the manufactures instructions (ThermoFisher). PBMCs were incubated with the following gene- 
specific probes: SLC2A10 (AF647 - Type 1 probe set), SLC2A8 (AF488 - Type 4 probe set), SLC2A1 (AF750 - Type 6 probe set). Samples were analysed immediately as described above.

\section{Proliferation assays}

CD45RA/CD27 sorted CD4 ${ }^{+}$and $\mathrm{CD}^{+} \mathrm{T}$ cells were stimulated with $0.5 \mu \mathrm{g} / \mathrm{ml}$ plate coated anti-CD3 (OKT3) and $5 \mathrm{ng} / \mathrm{ml} \mathrm{IL-2} \mathrm{for} 3$ days and proliferation was assessed by staining for the cell cycle related nuclear antigen Ki67 as described above.

\section{Transmission electron microscopy studies}

CD27/CD45RA defined $\mathrm{CD}^{+}$and $\mathrm{CD}^{+}$EMRA T cell subsets were isolated and fixed in $2 \%$ paraformaldehyde, $1.5 \%$ glutaraldehyde in $0.1 \mathrm{~m}$ phosphate buffer $\mathrm{pH}$ 7.3. They were then osmicated in $1 \%$ OsO4 in $0.1 \mathrm{M}$ phosphate buffer, dehydrated in a graded ethanol-water series, cleared in propylene oxide and infiltrated with Araldite resin. Ultra-thin sections were cut using a diamond knife, collected on 300 mesh grids, and stained with uranyl acetate and lead citrate. The cells were viewed in a Jeol 1010 transmission electron microscope (Jeol) and imaged using a Gatan Orius CCD camera (Gatan). Mitochondrial volume density (percentage of $\mathrm{T}$ cell volume occupied by mitochondria) was determined from EM images using a point-counting method using image J.

\section{Mitochondrial measurements}

Mitochondrial mass was assessed by incubating labelled PBMCs with $100 \mathrm{nM}$ of MitoTracker Green FM (ThermoFisher) for 30 minutes at $37^{\circ} \mathrm{C}, 5 \% \mathrm{CO}_{2}$. Mitochondrial membrane potential was investigated using TMRE (ThermoFisher), $1 \mu \mathrm{M}$ TMRE was incubated with labelled PBMCs for 30 minutes at $37^{\circ} \mathrm{C}, 5 \% \mathrm{CO}_{2}$. Mitochondrial ROS was measured using MitoSOX (ThermoFisher), $2 \mu \mathrm{M}$ MitoSOX was incubated with labelled PBMCs for 20 minutes at $37^{\circ} \mathrm{C}, 5 \% \mathrm{CO}_{2}$. Unfixed samples were immediately collected on a LSR II (BD Bioscience).

\section{ATP determination}


Intracellular ATP levels were measured ex vivo on sorted $\mathrm{CD} 4^{+}$and $\mathrm{CD} 8^{+} \mathrm{T}$ cell subsets via a bioluminescence assay according to the manufactures instructions (ThermoFisher).

\section{Metabolic assays}

Oxygen consumption rates (OCR) and extracellular acidification rates (ECAR) were measured in CD45RA/CD27 sorted CD4 ${ }^{+}$and $\mathrm{CD}^{+} \mathrm{T}$ cell subsets following 15 minute stimulation with $1 \mu \mathrm{g} / \mathrm{ml}$ anti-CD3 and $5 \mathrm{ng} / \mathrm{ml} \mathrm{IL-2.} \mathrm{The} \mathrm{assay} \mathrm{was} \mathrm{performed} \mathrm{in} \mathrm{RPMI} \mathrm{without} \mathrm{phenol} \mathrm{red} \mathrm{and} \mathrm{carbonate}$ buffer (Sigma) containing $25 \mathrm{mM}$ glucose, $2 \mathrm{nM}$ L-glutamine and $1 \mathrm{mM}$ pyruvate. The metabolic stress test was performed using $1 \mu \mathrm{M}$ oligomycin, $1.5 \mu \mathrm{M}$ fluorocarbonyl cyanide phenylhydrazone (FCCP), $100 \mathrm{nM}$ rotenone and $1 \mu \mathrm{M}$ antimycin A (Sigma) with the XF-96 Extracellular Flux Analyzer (Agilent). Glycolysis was examined via extracellular acidification rate (ECAR) in assay buffer excluding glucose, following injection with $10 \mathrm{mM}$ glucose, $1 \mu \mathrm{M}$ oligomycin and $100 \mathrm{mM} 2$ deoxy-D-glucose (2-DG; Sigma).

\section{Glucose and lipid uptake assays}

To assess glucose and lipid uptake in T cell subsets, PBMCs were incubated with anti-CD3 (1 $\mu \mathrm{g} / \mathrm{ml}$ ) for $30 \mathrm{~min}$ at $37^{\circ} \mathrm{C}$. Cells were subsequently incubated with $1 \mathrm{nM}$ Bodipy $\mathrm{FL} \mathrm{C} \mathrm{C}_{16}$ or $100 \mu \mathrm{M} 2$ NBDG, both from ThermoFisher in PBS and incubated for 15 minutes in media containing no glucose or serum. Samples were then analysed by flow cytometry.

\section{Transwell migration assay}

HUVECs monolayers were grown to confluence on transwell membranes (Corning) in the presence of $20 \%$ autologous donor sera or $10 \mathrm{ng} / \mathrm{ml}$ IFN $\gamma$ (R\&D Systems). PBMCs from healthy donors were placed in M199 medium (Sigma) in the top well and the chemoattractant in the bottom well, which was either $20 \%$ autologous donor sera or $1 \mathrm{~g} / \mathrm{ml} \mathrm{CXCL10}$ and CXCL12 (R\&D Systems). Cell migration was assessed after incubation at $37^{\circ} \mathrm{C}$ for $4 \mathrm{~h}$, each condition was set up in duplicate transwells. Migrated T cells were then collected from the top and bottom wells respectively, stained with phenotypic markers and quantified for a fixed period of time ( 3 min) by 
flow cytometer. Counting beads (BD Bioscience) were also run to enumerate the total number of cell to have transmigrated.

\section{Rotenone cultures}

Purified $\mathrm{CD}^{+} \mathrm{T}$ cells were incubated for 5 days with $10 \mathrm{nM}$ rotenone (Sigma) or DMSO control after which time the cells were used for metabolic assessment: mitochondrial mass, p53 levels and extracellular flux analysis as describe above. For long term rotenone cultures, $10 \mathrm{nM}$ rotenone was plated together with $0.2 \times 10^{6} \mathrm{CD}^{+} \mathrm{T}$ cells and $0.5 \mu \mathrm{g} / \mathrm{ml}$ anti-CD3 and $5 \mathrm{ng} / \mathrm{ml} \mathrm{IL-2}$. Cells were counted every $4 / 5$ days and population doubling was calculated using the following equation: $P D=$ $\log 10(\mathrm{Nf} / \mathrm{Ni}) / \log (2), \mathrm{Nf}=$ number of cells harvested, $\mathrm{Ni}=$ initial cell number seeded.

\section{Statistical analysis}

GraphPad Prism was used to perform statistical analysis. Statistical significance was evaluated using the paired Student $t$-test. Differences were considered significant when $P$ was $<0.05$. 


\section{References}

1. Akbar AN, Beverley PC, Salmon M. Will telomere erosion lead to a loss of T-cell memory? Nat Rev Immunol 2004, 4(9): 737-743.

2. Akbar AN, Henson SM, Lanna A. Senescence of T Lymphocytes: Implications for Enhancing Human Immunity. Trends Immunol 2016, 37(12): 866-876.

3. Franceschi C, Bonafe M, Valensin S, Olivieri F, De Luca M, Ottaviani E, et al. Inflamm-aging. An evolutionary perspective on immunosenescence. Ann N Y Acad Sci 2000, 908: 244-254.

4. Calder PC, Bosco N, Bourdet-Sicard R, Capuron L, Delzenne N, Dore J, et al. Health relevance of the modification of low grade inflammation in ageing (inflammageing) and the role of nutrition. Ageing Res Rev 2017, 40: 95-119.

5. Weng NP, Akbar AN, Goronzy J. CD28(-) T cells: their role in the age-associated decline of immune function. Trends Immunol 2009, 30(7): 306-312.

6. Parish ST, Wu JE, Effros RB. Sustained CD28 expression delays multiple features of replicative senescence in human CD8 T lymphocytes. J Clin Immunol 2010, 30(6): 798-805.

7. Henson SM, Macaulay R, Riddell NE, Nunn CJ, Akbar AN. Blockade of PD-1 or p38 MAP kinase signaling enhances senescent human CD8+ T-cell proliferation by distinct pathways. Eur J Immunol 2015, 45(5): 1441-1451.

8. Henson SM, Lanna A, Riddell NE, Franzese O, Macaulay R, Griffiths SJ, et al. p38 signaling inhibits mTORC1-independent autophagy in senescent human CD8+ T cells. J Clin Invest 2014, 124(9): 4004-4016.

9. Czesnikiewicz-Guzik M, Lee WW, Cui D, Hiruma Y, Lamar DL, Yang ZZ, et al. T cell subsetspecific susceptibility to aging. Clin Immunol 2008, 127(1): 107-118.

10. Goronzy JJ, Lee WW, Weyand CM. Aging and T-cell diversity. Exp Gerontol 2007, 42(5): 400-406.

11. Macintyre AN, Gerriets VA, Nichols AG, Michalek RD, Rudolph MC, Deoliveira D, et al. The glucose transporter Glut1 is selectively essential for CD4 T cell activation and effector function. Cell Metab 2014, 20(1): 61-72.

12. Cao Y, Rathmell JC, Macintyre AN. Metabolic reprogramming towards aerobic glycolysis correlates with greater proliferative ability and resistance to metabolic inhibition in CD8 versus CD4 T cells. PLoS One 2014, 9(8): e104104.

13. Appay V, van Lier RA, Sallusto F, Roederer M. Phenotype and function of human $T$ lymphocyte subsets: consensus and issues. Cytometry A 2008, 73(11): 975-983.

14. Di Mitri D, Azevedo RI, Henson SM, Libri V, Riddell NE, Macaulay R, et al. Reversible Senescence in Human CD4+CD45RA+CD27- Memory T Cells. J Immunol 2011, 187(5): 2093-2100. 
15. Cui H, Kong Y, Zhang H. Oxidative stress, mitochondrial dysfunction, and aging. J Signal Transduct 2012, 2012: 646354-646354.

16. Shen Y, Wen Z, Li Y, Matteson EL, Hong J, Goronzy JJ, et al. Metabolic control of the scaffold protein TKS5 in tissue-invasive, proinflammatory T cells. Nat Immunol 2017, 18(9): 1025-1034.

17. Brewer RA, Gibbs VK, Smith DL, Jr. Targeting glucose metabolism for healthy aging. Nutr Healthy Aging 2016, 4(1): 31-46.

18. Callender LA, Carroll EC, Beal RWJ, Chambers ES, Nourshargh S, Akbar AN, et al. Human CD8(+) EMRA T cells display a senescence-associated secretory phenotype regulated by p38 MAPK. Aging Cell 2018, 17(1).

19. Mueckler M, Thorens B. The SLC2 (GLUT) family of membrane transporters. Mol Aspects Med 2013, 34(2-3): 121-138.

20. Muller PAJ, Vousden $\mathrm{KH}$, Norman JC. p53 and its mutants in tumor cell migration and invasion. J Cell Biol 2011, 192(2): 209-218.

21. Oswald-Richter K, Grill SM, Leelawong M, Tseng M, Kalams SA, Hulgan T, et al. Identification of a CCR5-expressing $\mathrm{T}$ cell subset that is resistant to R5-tropic HIV infection. PLoS Pathog 2007, 3(4): e58.

22. Hess C, Means TK, Autissier P, Woodberry T, Altfeld M, Addo MM, et al. IL-8 responsiveness defines a subset of CD8 T cells poised to kill. Blood 2004, 104(12): 3463-3471.

23. Brainard DM, Tager AM, Misdraji J, Frahm N, Lichterfeld M, Draenert R, et al. Decreased CXCR3+ CD8 T Cells in Advanced Human Immunodeficiency Virus Infection Suggest that a Homing Defect Contributes to Cytotoxic T-Lymphocyte Dysfunction. J Virol 2007, 81(16): 8439-8450.

24. Kirkbride KC, Sung BH, Sinha S, Weaver AM. Cortactin: a multifunctional regulator of cellular invasiveness. Cell Adh Migr 2011, 5(2): 187-198.

25. Murphy DA, Courtneidge SA. The 'ins' and 'outs' of podosomes and invadopodia: characteristics, formation and function. Nat Rev Mol Cell Biol 2011, 12(7): 413-426.

26. Uruno T, Liu J, Zhang P, Fan Y, Egile C, Li R, et al. Activation of Arp2/3 complex-mediated actin polymerization by cortactin. Nat Cell Biol 2001, 3(3): 259-266.

27. Wang Y, Zhang YX, Kong CZ, Zhang Z, Zhu YY. Loss of P53 facilitates invasion and metastasis of prostate cancer cells. Mol Cell Biochem 2013, 384(1): 121-127.

28. Matoba S, Kang J-G, Patino WD, Wragg A, Boehm M, Gavrilova O, et al. p53 Regulates Mitochondrial Respiration. Science 2006, 312(5780): 1650-1653.

29. Qi Z, He J, Su Y, He Q, Liu J, Yu L, et al. Physical exercise regulates p53 activity targeting SCO2 and increases mitochondrial COX biogenesis in cardiac muscle with age. PloS one 2011, 6(7): e21140-e21140. 
30. Baker DJ, Wijshake T, Tchkonia T, LeBrasseur NK, Childs BG, van de Sluis B, et al. Clearance of p16Ink4a-positive senescent cells delays ageing-associated disorders. Nature 2011, 479(7372): 232-236.

31. Koch S, Larbi A, Derhovanessian E, Ozcelik D, Naumova E, Pawelec G. Multiparameter flow cytometric analysis of CD4 and CD8 T cell subsets in young and old people. Immun Ageing 2008, 5: 6 .

32. Akbar AN, Fletcher JM. Memory T cell homeostasis and senescence during aging. Curr Opin Immunol 2005, 17(5): 480-485.

33. Sun N, Youle RJ, Finkel T. The Mitochondrial Basis of Aging. Mol Cell 2016, 61(5): 654-666.

34. Corsetti G, Pasini E, D'Antona G, Nisoli E, Flati V, Assanelli D, et al. Morphometric Changes Induced by Amino Acid Supplementation in Skeletal and Cardiac Muscles of Old Mice. Am J Cardiol 2008, 101(11, Supplement): S26-S34.

35. Reznick RM, Zong H, Li J, Morino K, Moore IK, Yu HJ, et al. Aging-Associated Reductions in AMP-Activated Protein Kinase Activity and Mitochondrial Biogenesis. Cell Metab 2007, 5(2): 151-156.

36. Preston CC, Oberlin AS, Holmuhamedov EL, Gupta A, Sagar S, Syed RHK, et al. Aginginduced alterations in gene transcripts and functional activity of mitochondrial oxidative phosphorylation complexes in the heart. Mech Ageing Dev 2008, 129(6): 304-312.

37. Theurey P, Pizzo P. The Aging Mitochondria. Genes 2018, 9(1): 22.

38. Kaplon J, Zheng L, MeissI K, Chaneton B, Selivanov VA, Mackay G, et al. A key role for mitochondrial gatekeeper pyruvate dehydrogenase in oncogene-induced senescence. Nature 2013, 498: 109.

39. Davalli P, Mitic T, Caporali A, Lauriola A, D'Arca D. ROS, Cell Senescence, and Novel Molecular Mechanisms in Aging and Age-Related Diseases. Oxid Med Cell longev 2016, 2016: 3565127-3565127.

40. Ristow M, Zarse K. How increased oxidative stress promotes longevity and metabolic health: The concept of mitochondrial hormesis (mitohormesis). Exp Gerontol 2010, 45(6): 410-418.

41. Owusu-Ansah E, Song W, Perrimon N. Muscle Mitohormesis Promotes Longevity via Systemic Repression of Insulin Signaling. Cell 2013, 155(3): 699-712.

42. Nicholls DG. Mitochondrial membrane potential and aging. Aging Cell 2004, 3(1): 35-40.

43. Divakaruni AS, Brand MD. The regulation and physiology of mitochondrial proton leak. Physiol 2011, 26(3): 192-205.

44. Hagopian K, Harper ME, Ram JJ, Humble SJ, Weindruch R, Ramsey JJ. Long-term calorie restriction reduces proton leak and hydrogen peroxide production in liver mitochondria. $A m \mathrm{~J}$ Physiol Endocrinol Metab 2005, 288(4): E674-684. 
45. Speakman JR, Talbot DA, Selman C, Snart S, McLaren JS, Redman P, et al. Uncoupled and surviving: individual mice with high metabolism have greater mitochondrial uncoupling and live longer. Aging Cell 2004, 3(3): 87-95.

46. Pence BD, Yarbro JR. Aging impairs mitochondrial respiratory capacity in classical monocytes. Exp Gerontol 2018, 108: 112-117.

47. Callender LA, Carroll EC, Bober EA, Henson SM. Divergent mechanisms of metabolic dysfunction drive fibroblast and T-cell senescence. Ageing Res Rev 2018, 47: 24-30.

48. James EL, Michalek RD, Pitiyage GN, de Castro AM, Vignola KS, Jones J, et al. Senescent Human Fibroblasts Show Increased Glycolysis and Redox Homeostasis with Extracellular Metabolomes That Overlap with Those of Irreparable DNA Damage, Aging, and Disease. $J$ Proteome Res 2015, 14(4): 1854-1871.

49. Maedera S, Mizuno T, Ishiguro H, Ito T, Soga T, Kusuhara H. GLUT6 is a lysosomal transporter that is regulated by inflammatory stimuli and modulates glycolysis in macrophages. FEBS Lett 2019, 593(2): 195-208.

50. Zhao FQ, Keating AF. Functional properties and genomics of glucose transporters. Curr Genomics 2007, 8(2): 113-128.

51. Wang X, Eno Colins O, Altman Brian J, Zhu Y, Zhao G, Olberding Kristen E, et al. ER stress modulates cellular metabolism. Biochem J 2011, 435(1): 285-296.

52. Buck MD, O'Sullivan D, Klein Geltink RI, Curtis JD, Chang CH, Sanin DE, et al. Mitochondrial Dynamics Controls T Cell Fate through Metabolic Programming. Cell 2016, 166(1): 63-76.

53. Saurwein-TeissI M, Lung TL, Marx F, Gschösser C, Asch E, Blasko I, et al. Lack of Antibody Production Following Immunization in Old Age: Association with CD8+CD28- T Cell Clonal Expansions and an Imbalance in the Production of Th1 and Th2 Cytokines. $J$ Immunol 2002, 168(11): 5893-5899.

54. Dai C-Q, Luo T-T, Luo S-C, Wang J-Q, Wang S-M, Bai Y-H, et al. p53 and mitochondrial dysfunction: novel insight of neurodegenerative diseases. J Bioenerg Biomembr 2016, 48(4): 337-347.

55. Correia-Melo C, Marques FDM, Anderson R, Hewitt G, Hewitt R, Cole J, et al. Mitochondria are required for pro-ageing features of the senescent phenotype. EMBO J 2016, 35(7): 724742. 


\section{Figure legends}

Figure 1. Human $\mathrm{CD}^{+}$EMRA T cells are acquired at a slower rate owing to a higher degree of mitochondrial content.

(A) The accumulation of senescent $\mathrm{CD} 4^{+}$and $\mathrm{CD} 8^{+} \mathrm{T}$ cells with age defined by the markers CD45RA and CD27. (B) Representative flow cytometry plots and cumulative graphs of mitotracker green staining in $\mathrm{CD}^{+}$and $\mathrm{CD}^{+}$EMRA T cells analysed directly ex vivo. Data expressed as mean \pm SEM of 6 donors. (C) Electron microscope images of CD4 ${ }^{+}$and CD8 ${ }^{+}$ EMRA T cells imaged directly ex vivo. Yellow arrows mark mitochondria. Graph shows the percentage by cell volume of mitochondria in senescent $\mathrm{T}$ cell subsets determined by a point counting grid method from 20 different electron microscope images. (D) PGC1a expression in CD45RA/CD27 defined EMRA T cell subsets. Data expressed as mean \pm SEM of 9 donors. p-values were calculated using a T-test.

Figure 2. Mitochondrial dysfunction is observed $\mathrm{CD}^{+}$but not $\mathrm{CD}^{+}$EMRA T cell subsets.

(A) Representative flow cytometry plots and cumulative graphs of TMRE staining showing membrane potential in CD45RA/CD27 T cell subsets directly ex vivo. defined showing the percentage of cortactin positive (a) $\mathrm{CD}^{+}$and (b) $\mathrm{CD}^{+} \mathrm{T}$ cells analysed directly ex vivo. Data expressed as mean \pm SEM of 6 donors. (B) Mitochondrial ROS measured using MitoSox by flow cytometry in $\mathrm{CD}^{+}$and $\mathrm{CD}^{+}$EMRA T cells. Data expressed as mean $\pm \mathrm{SEM}$ of 6 donors. (C) Mitochondrial ROS production expressed as a ratio of mitochondrial mass. (D) $\gamma \mathrm{H} 2 \mathrm{AX}$ expression as determined by flow cytometry in CD45RA/CD27 defined T cell subsets directly ex vivo, the graph shows the mean \pm SEM for 5 donors. (E) Oxygen consumption rates (OCR) of the EMRA CD4 ${ }^{+}$and $\mathrm{CD}^{+} \mathrm{T}$ cells subsets were measured following a 15 minute stimulated with $0.5 \mu \mathrm{g} / \mathrm{ml}$ anti-CD3 and $5 \mathrm{ng} / \mathrm{ml} \mathrm{IL-2,} \mathrm{the} \mathrm{cells} \mathrm{were} \mathrm{then} \mathrm{subjected} \mathrm{to}$ a metabolic stress test using the indicated mitochondrial inhibitors. Data are representative of 4 independent experiments. (F) The basal OCR, extracellular acidification rate (ECAR) 
and spare respiratory capacity were measured following a 15 minute stimulation with 0.5 $\mu \mathrm{g} / \mathrm{ml}$ anti-CD3 and $5 \mathrm{ng} / \mathrm{ml} \mathrm{IL-2.} \mathrm{Graphs} \mathrm{show} \mathrm{the} \mathrm{mean} \pm$ SEM for 4 donors. (G) ATP concentration in EMRA T cell subsets, graphs show the mean \pm SEM for 5 donors. p-values were calculated using a T-test.

\section{Figure 3. Impaired nutrient uptake by CD8 ${ }^{+}$EMRA T cells.}

(A) Glucose uptake was assessed using the fluorescent glucose analog 2-NBDG in CD4 ${ }^{+}$ and $\mathrm{CD}^{+}{ }^{\mathrm{T}}$ CD45RA/CD27 defined EMRA T cells by flow cytometry following a 15 minute incubation. Data expressed as mean \pm SEM of 7 donors. (B) Examples and data showing expression of the glucose transporters glut1 -8 and -10 in senescent T cells subsets directly ex vivo. Graphs show the mean \pm SEM for 4 donors. (C) Lipid uptake was measured using fluorescently labelled palmitate, BODIPY C16 by flow cytometry following a 15 minute incubation in $\mathrm{CD}^{+}$and $\mathrm{CD} 8^{+}$EMRA T cells. Data expressed as mean \pm SEM of 7 donors. (D) Examples and graphs showing the fatty acid translocase CD36 and FATP2 and -3 directly ex vivo. Data expressed as mean \pm SEM of 6 donors. p-values were calculated using a T-test.

\section{Figure 4. Impaired function observed in CD8+ EMRA T cells.}

(A) Example and graph showing the expression of p-p53 in $\mathrm{CD}^{+}$and $\mathrm{CD} 8^{+} \mathrm{CD} 45 \mathrm{RA} / \mathrm{CD} 27$ define EMRA T cells directly ex vivo. Graphs show the mean \pm SEM for 4 donors. (B) Proliferation was defined in senescent T cell subsets using Ki67 directly ex vivo. Data show the mean \pm SEM for 12 donors. (C) The migration of $\mathrm{CD}^{+}$and $\mathrm{CD} 8^{+}$EMRA T cells through HUVECs and their supporting transwell filters. HUVECs were stimulated with $20 \%$ decomplemented (heated at $56^{\circ} \mathrm{C}$ for $20 \mathrm{~min}$ ) autologous donor sera for $24 \mathrm{~h}$. PBMCs were allowed to adhere and migrate for $4 \mathrm{~h}$ towards either media, CXCL10/12 or autologous serum. The number of $T$ cells were counted and expressed as a percentage of the total $\mathrm{CD}^{+}$or $\mathrm{CD}^{+} \mathrm{T}$ cell subset added. Data are expressed as the mean $\pm \mathrm{SEM}$ of 6 donors. (D) 
Representative flow cytometry plots and cumulative graphs showing the percentage of cortactin positive senescent $\mathrm{T}$ cell subsets analysed directly ex vivo. Data expressed as mean \pm SEM of 7 donors. p-values were calculated using a T-test.

\section{Figure 5. Impairing mitochondrial function in $\mathrm{CD}^{+} \mathrm{T}$ cells accelerates senescence.}

(A) Example and graph showing the mitochondrial mass of $\mathrm{CD}^{+} \mathrm{T}$ cells treated for 5 days with $10 \mathrm{nM}$ rotenone or DMSO control. Graph show the mean \pm SEM for 3 donors (B) Extracellular acidification rates (ECAR) of the rotenone or DMSO treated $\mathrm{CD}^{+} \mathrm{T}$ cells or DMSO treated CD8+ T cell were measured following a 15 minute stimulation with $0.5 \mu \mathrm{g} / \mathrm{ml}$ anti-CD3 and $5 \mathrm{ng} / \mathrm{ml} \mathrm{IL-2}$. The cells were then subjected to a glycolytic rate assay using the indicated substances. Data are representative of 3 independent experiments. (C) The basal ECAR and glycolytic capacity were measured following a 15 minute stimulation with 0.5 $\mu \mathrm{g} / \mathrm{ml}$ anti-CD3 and $5 \mathrm{ng} / \mathrm{ml} \mathrm{IL-2}$. Graphs show the mean \pm SEM for 3 donors. (D) Example and graph showing the expression of $\mathrm{p}-\mathrm{p} 53$ in $\mathrm{CD}^{+} \mathrm{T}$ cells treated for 5 days with $10 \mathrm{nM}$ rotenone or DMSO control. Graphs show the mean \pm SEM for 3 donors. (E) Population doublings for $\mathrm{CD}^{+} \mathrm{T}$ cells treated $10 \mathrm{nM}$ rotenone or DMSO control over 27 days. Graphs show the mean \pm SEM for 3 donors. 
A

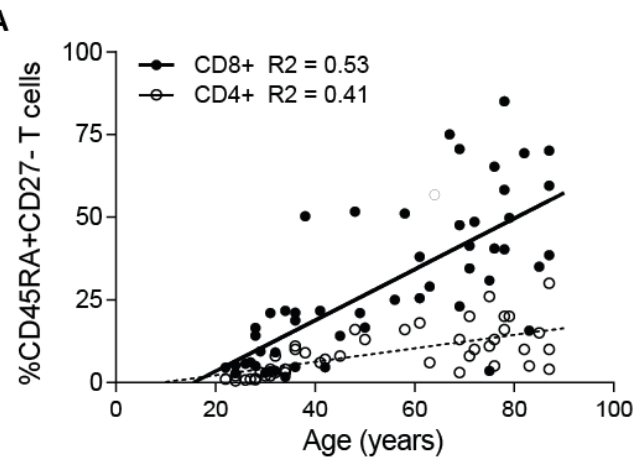

C

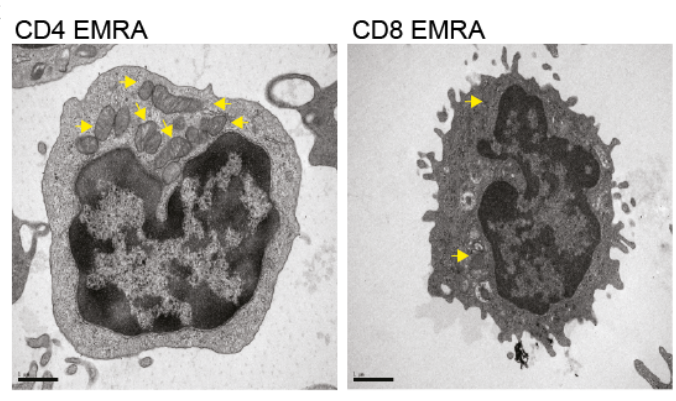

B
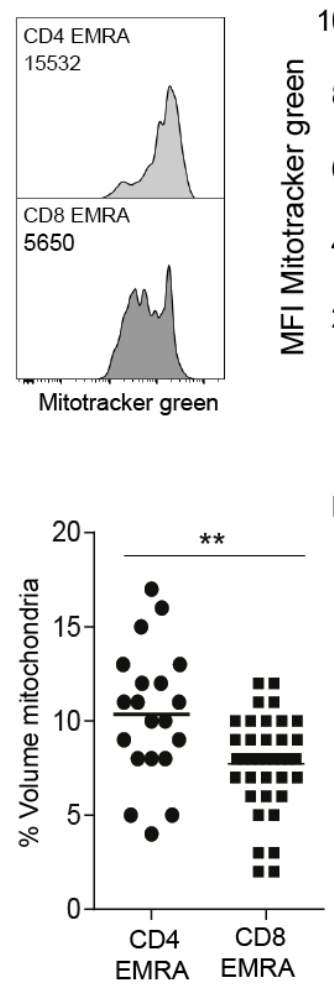

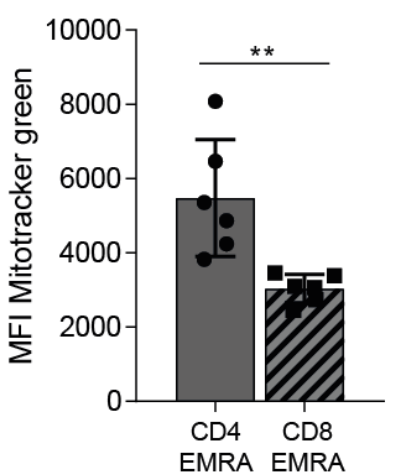

D

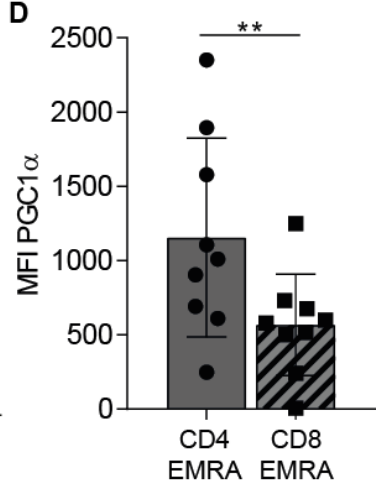

Figure 1 
Figure 2.

A

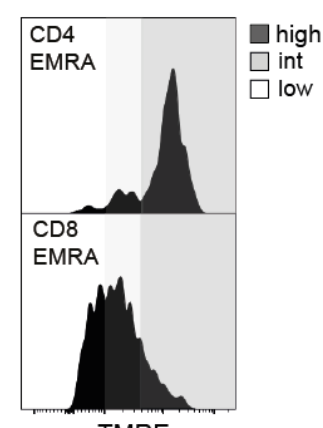

TMRE

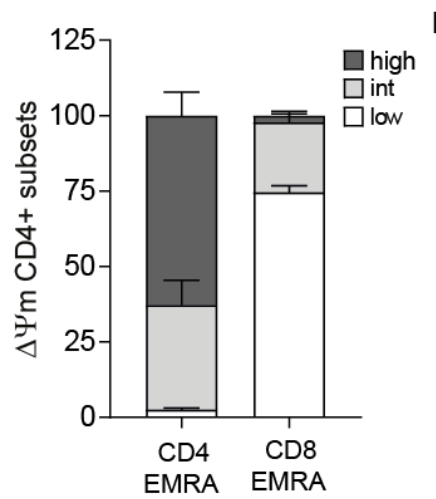

D

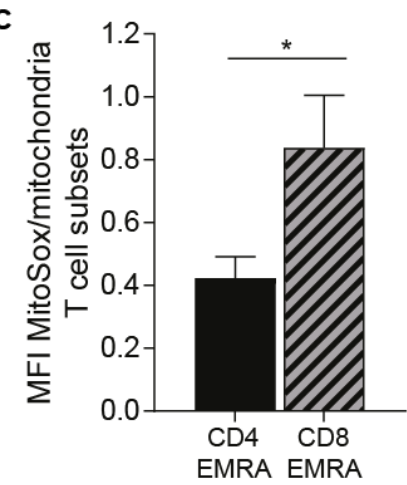

E

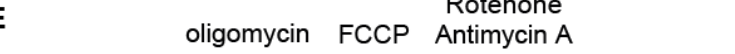

B

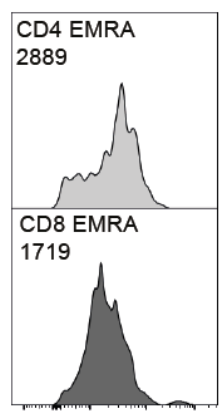

MitoSox

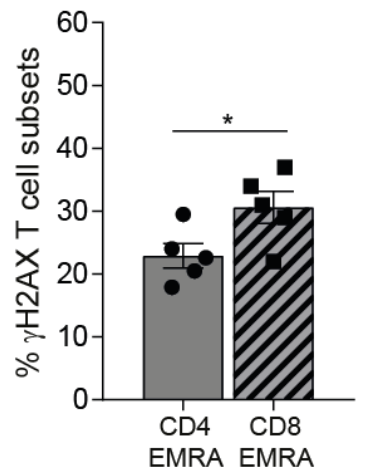

F

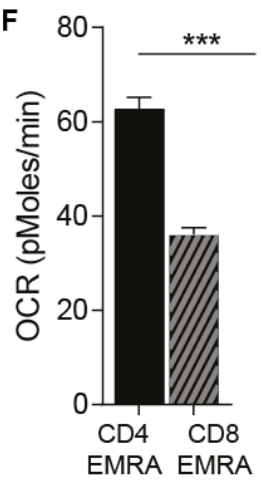

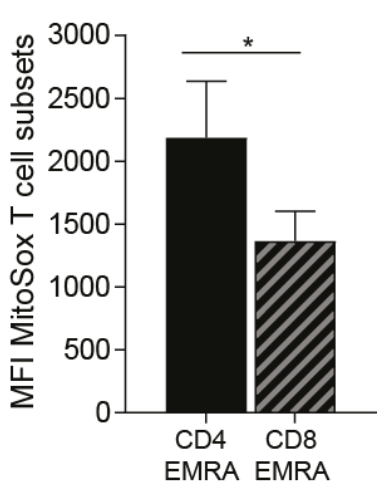

EMRA EMRA
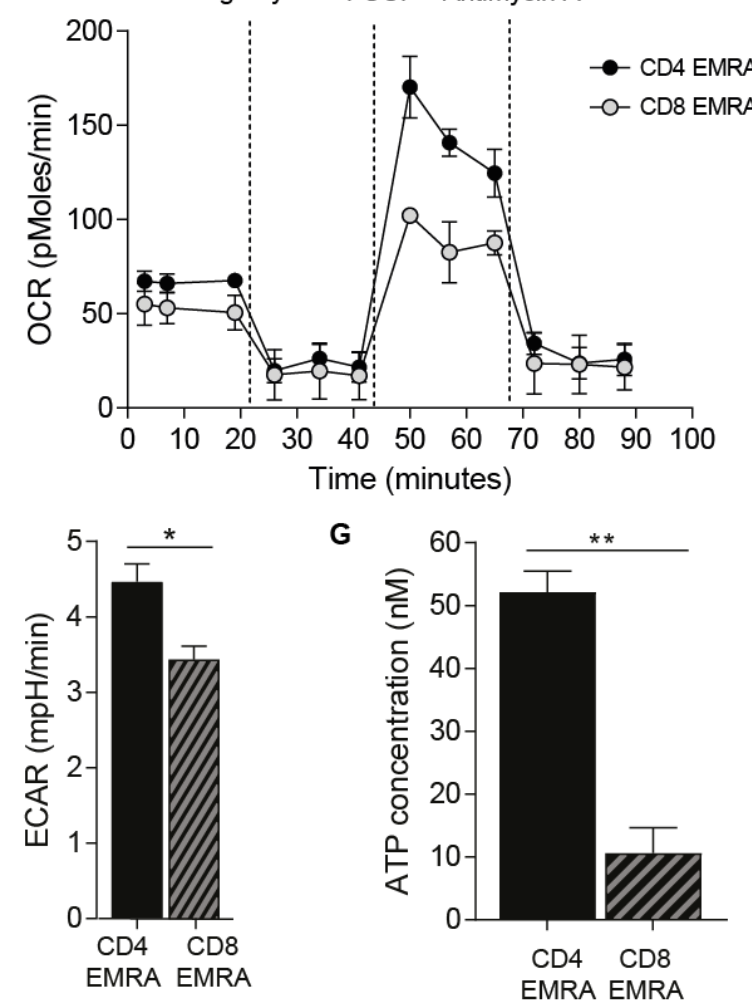

G

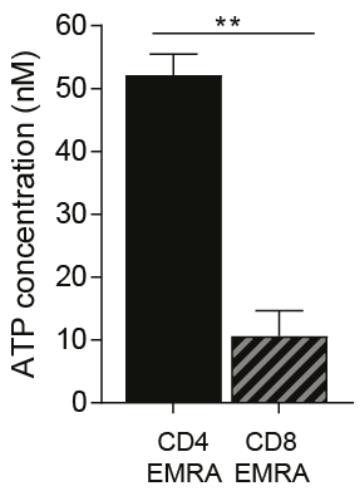


Figure 3.

A
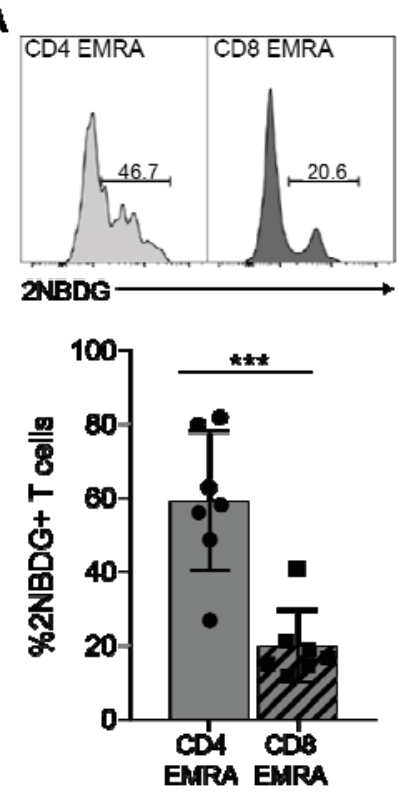

C
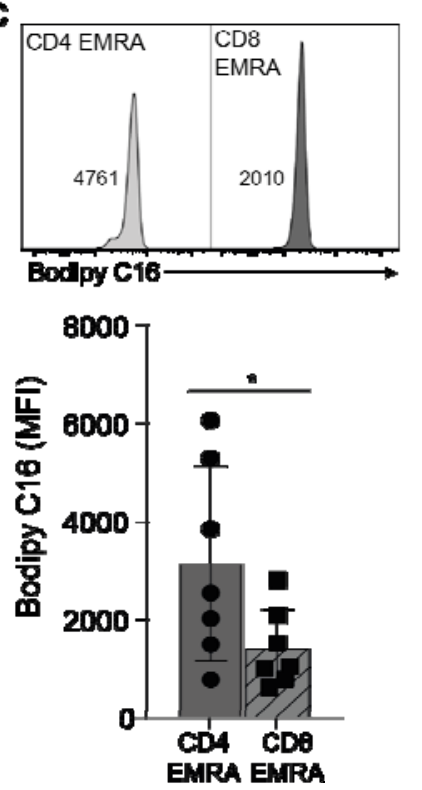

$\mathbf{B}$
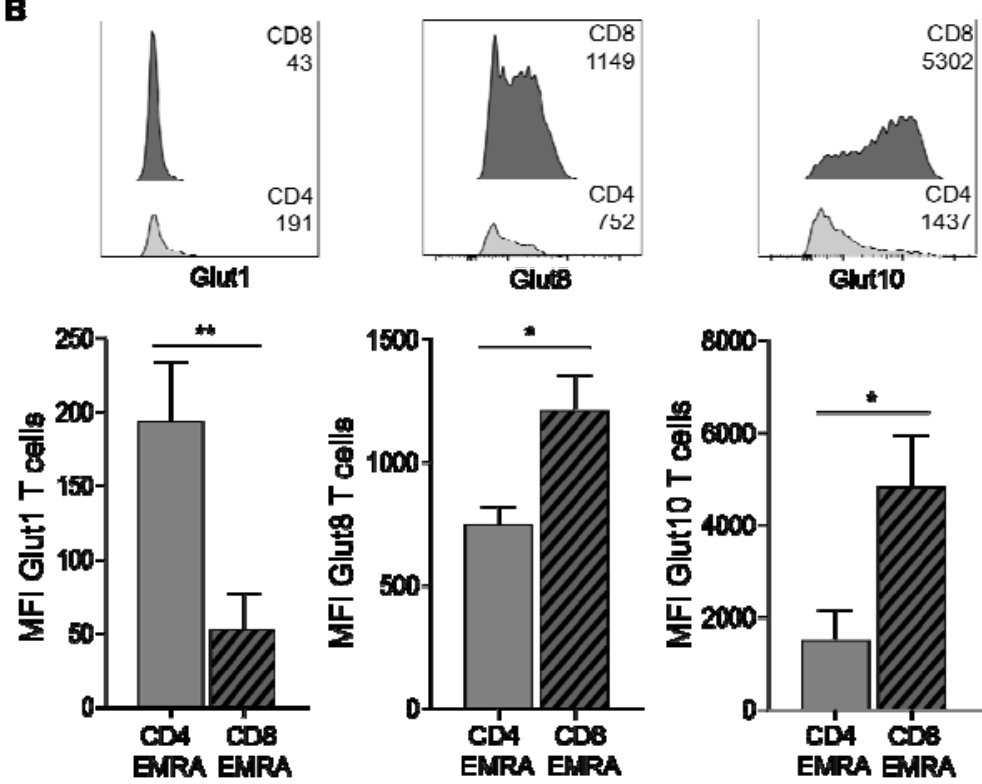

D
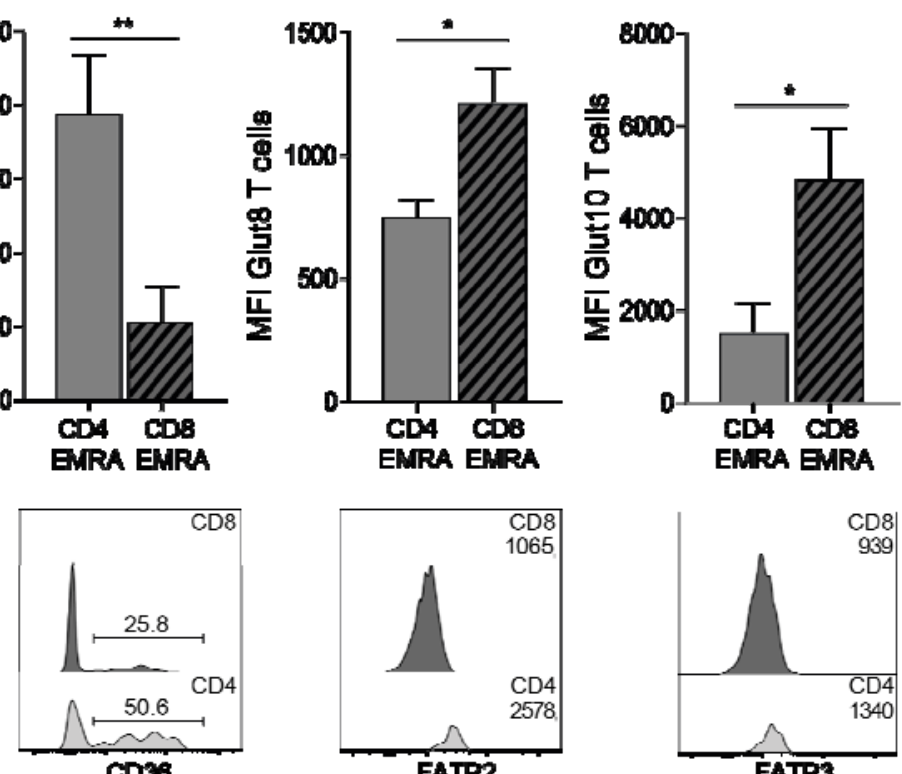

$\mathbf{D}$
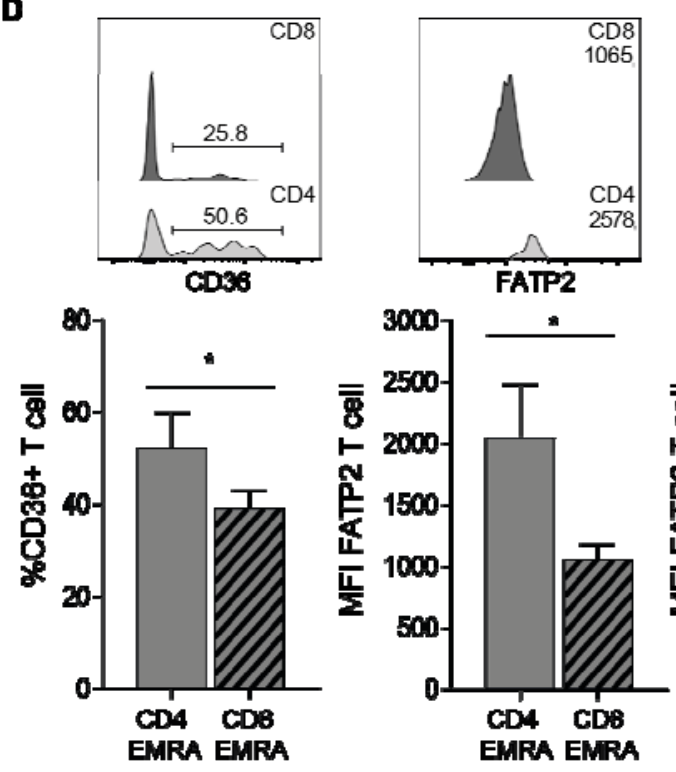
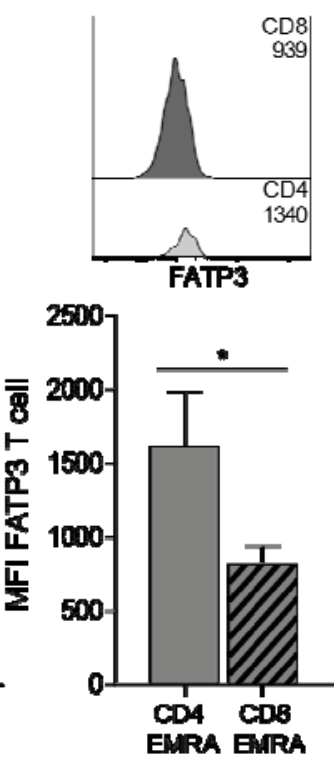


\section{Figure 4.}

A

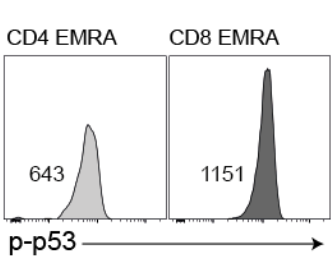

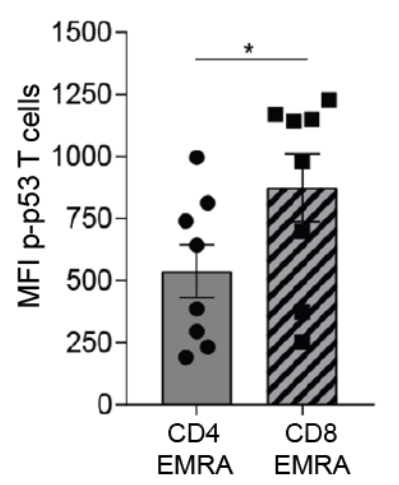

C
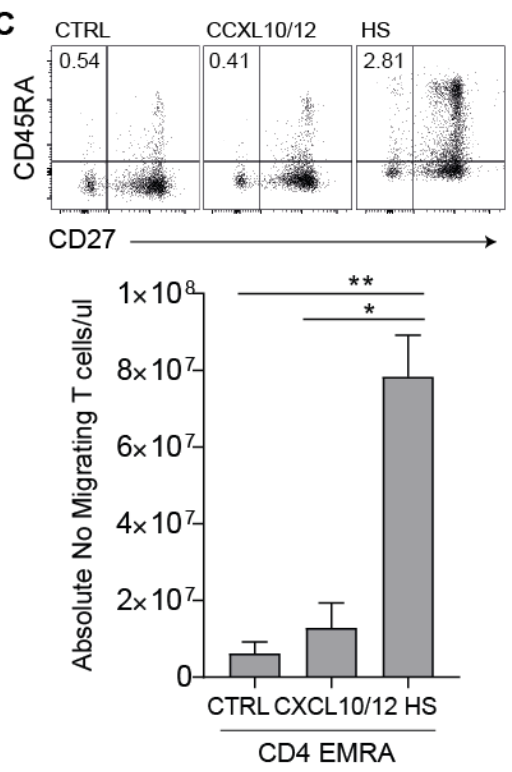

B

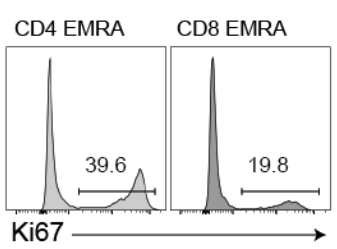

Ki67

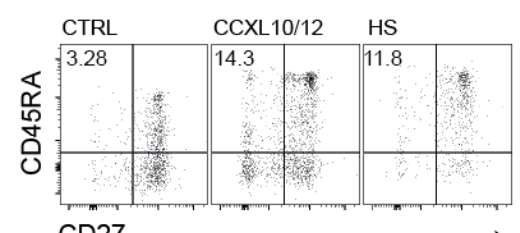

CD27

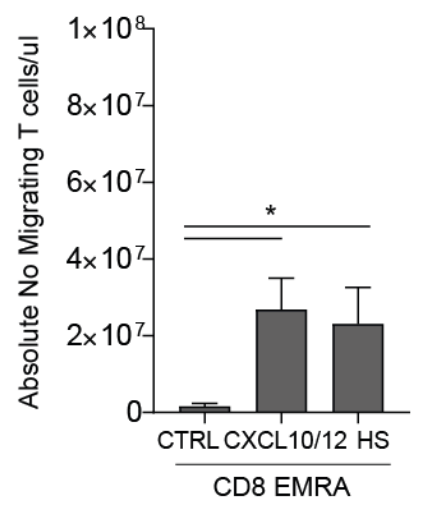

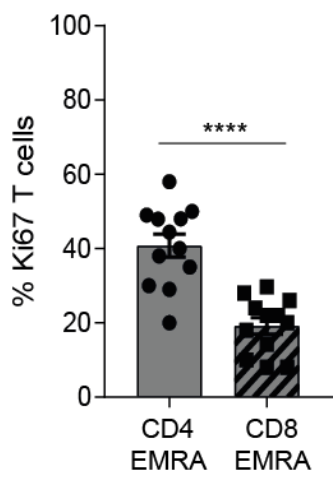

D
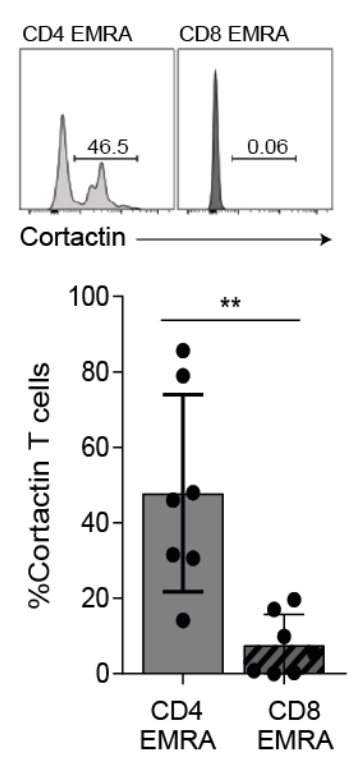


\section{Figure 5}

A

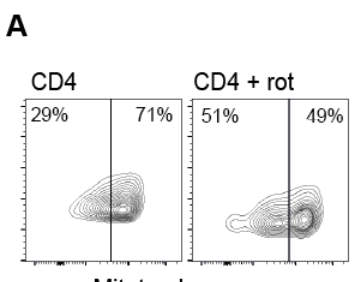

Mitotracker green

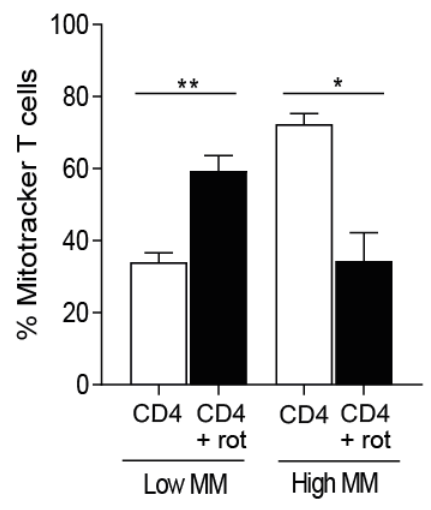

D

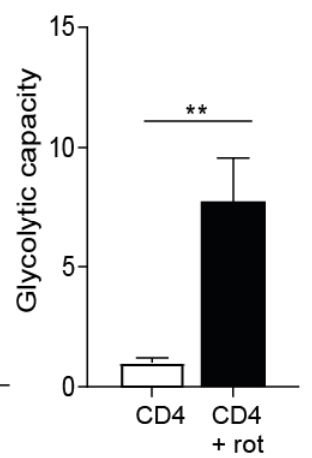

D
B
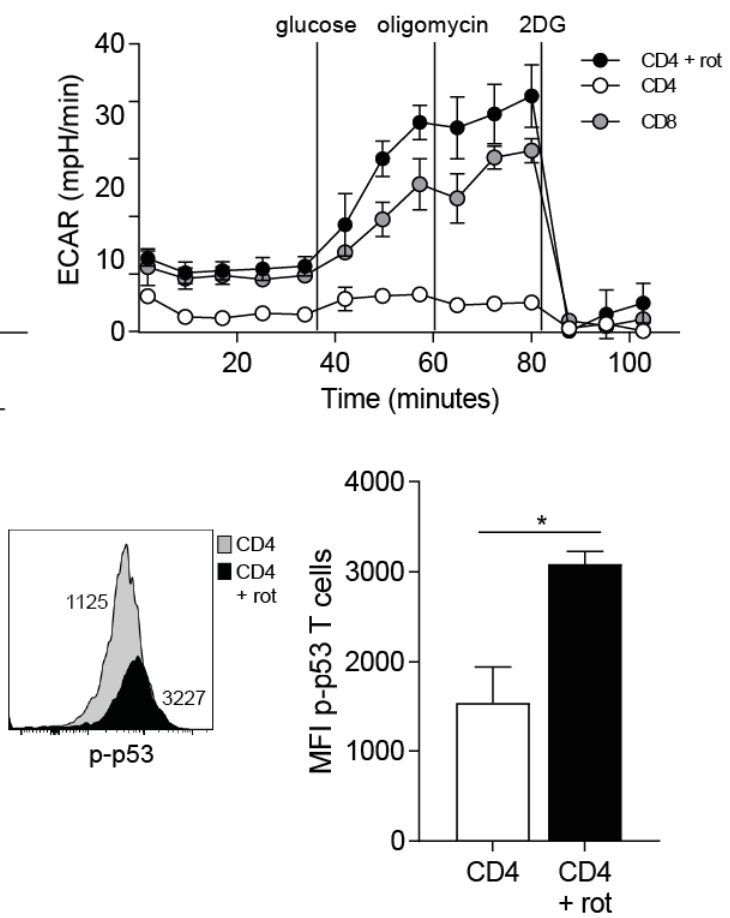

E

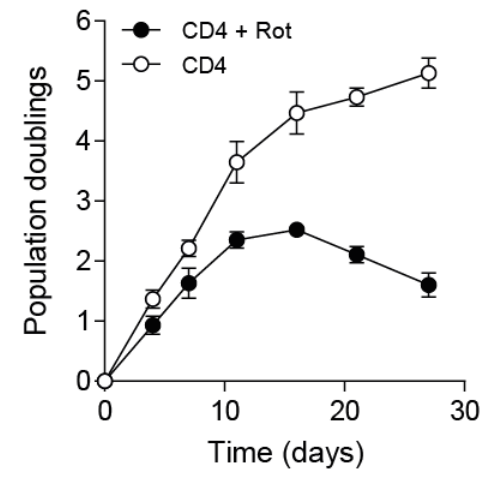

